\title{
Review \\ Knockout and transgenic mice of Trp53: what have we learned about p53 in breast cancer?
}

Anneke C Blackburn and D Joseph Jerry

Department of Veterinary and Animal Sciences, University of Massachusetts, Amherst, Massachusetts, USA

Correspondence: Joseph Jerry, Department of Veterinary and Animal Sciences, Paige Laboratory, University of Massachusetts, Amherst, MA 01003-6410, USA. Tel: +1 413545 5335; fax: +1 413545 6326; e-mail: jjerry@vasci.umass.edu

Received: 8 February 2002

Revisions requested: 8 March 2002

Revisions received: 15 March 2002

Accepted: 25 March 2002

Published: 18 April 2002
Breast Cancer Res 2002, 4:101-111

(C) 2002 BioMed Central Ltd

(Print ISSN 1465-5411; Online ISSN 1465-542X)

\begin{abstract}
The human p53 tumor suppressor gene TP53 is mutated at a high frequency in sporadic breast cancer, and Li-Fraumeni syndrome patients who carry germline mutations in one TP53 allele have a high incidence of breast cancer. In the 10 years since the first knockout of the mouse p53 tumor suppressor gene (designated Trp53) was published, much has been learned about the contribution of p53 to biology and tumor suppression in the breast through the use of p53 transgenic and knockout mice. The original mice deficient in p53 showed no mammary gland phenotype. However, studies using BALB/c-Trp53-deficient mice have demonstrated a delayed involution phenotype and a mammary tumor phenotype. Together with other studies of mutant p53 transgenes and p53 bitransgenics, a greater understanding has been gained of the role of p53 in involution, of the regulation of p53 activity by hormones, of the effect of mouse strain and modifier genes on tumor phenotype, and of the cooperation between p53 and other oncogenic pathways, chemical carcinogens and hormonal stimulation in mammary tumorigenesis. Both p53 transgenic and knockout mice are important in vivo tools for understanding breast cancer, and are yet to be exploited for developing therapeutic strategies in breast cancer.
\end{abstract}

Keywords: breast cancer, knockout, p53, transgenic

\section{Introduction}

The p53 tumor suppressor gene (TP53 in humans or Trp53 in mice) is critical for inhibiting tumor development in many tissues. This is evident in breast epithelium from the high frequency of mutations in TP53 in sporadic human breast cancers [1]. Consistent with this phenomenon, germline mutations in p53 predispose women to breast cancer. Li-Fraumeni syndrome (LFS) patients, of whom approximately one-half carry mutations in one allele of TP53 [2], suffer from a high frequency of breast cancer, with early-onset breast cancer accounting for approximately one-half of the tumors observed in LFS women
$[3,4]$. Furthermore, even in the context of mutations in the breast cancer susceptibility genes BRCA1 and BRCA2, high rates of p53 mutation are found $[5,6]$. Thus, p53 appears to be a critical agent in the protection of the breast epithelium against tumorigenesis.

The way in which p53 performs its tumor suppressor role involves diverse cellular processes. The repertoire of p53 activities includes the regulation of the cell cycle, apoptosis, senescence, facilitating DNA repair, and antagonizing angiogenesis (Fig. 1). Many of these functions are mediated by transcriptional activation of target genes by p53 [7], 
Figure 1

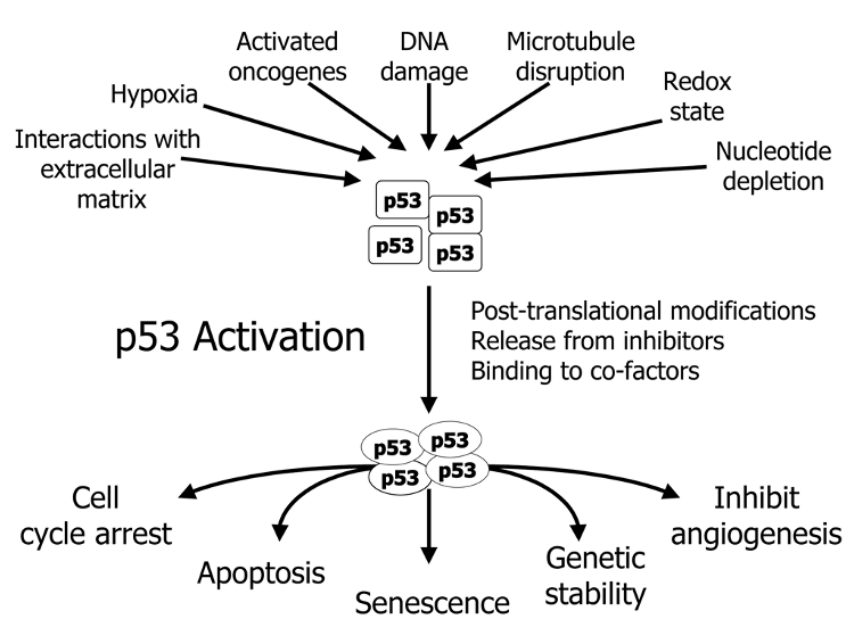

Activation of $\mathrm{p} 53$ and responses. The p53 protein can exist in multiple states within cells. Under normal conditions, levels of p53 protein are very low due to rapid turnover. Activation of cellular stress pathways causes covalent modification and tetramerization of p53, stabilizing the protein and leading to accumulation within the nucleus. The cellular outcome depends on the balance of factors present in cells that may antagonize or promote particular responses.

such as the induction of cell-cycle arrest by transcriptional activation of p21WAF1, a cyclin-dependent kinase inhibitor. Other activities may involve the p53 protein more directly, such as the $3^{\prime} \rightarrow 5^{\prime}$ exonuclease activity of p53 that may contribute to fidelity of DNA replication [8].

The p53 protein levels are normally very low, due to rapid turnover, but in response to various stressful stimuli, such as DNA damage or hypoxia, the p53 protein is stabilized and activated to perform its functions. The regulation of p53 stability and activity involves many proteins, such as the antagonist MDM2 that binds the transactivation domain and also targets p53 for ubiquitination and degradation, or the kinases DNA-PK and ATM that phosphorylate p53 at several of its many sites for post-translational modification $[9,10]$. The overall p53 response of a cell thus depends on the integration of the signals and activities of many different mechanisms and proteins. The important consequences of p53 activity, potentially cell death or tumor promotion, require this fineness and multiplicity of controls.

With this level of control over p53 function, it is not surprising that loss or mutation of one allele of p53 can have serious consequences. This is the case in LFS patients, who are susceptible to a wide range of tumor types in addition to breast cancer $[3,4]$. In contrast with Knudson's two-hit hypothesis for tumor suppressor genes, however, tumors can develop in Trp53 $3^{+/-}$mice while still retaining a functional wild-type Trp53 allele, indicating that p53 is haploinsufficient for tumor suppression [11]. The reduc- tion in p53 dosage that results from heterozygosity at the genetic level has been shown in many mouse tissues to result in an intermediate level of transcriptional activity, growth control and apoptosis compared with wild-type and $\operatorname{Trp53}{ }^{-/-}$cells [12-14]. This may lead to the retention of cells that have acquired further oncogenic mutations, thus resulting in haploinsufficiency for tumor suppression.

The protection of the mammary epithelium against tumorigenesis by p53 may thus involve many different processes. While the fine details of mechanisms and regulation are best addressed in highly manipulable in vitro systems, the biological consequences of such findings need to be verified in vivo where all the signals from the whole tissue and whole animal are intact. Studies in transgenic and knockout mice on the role of p53 and other molecules in breast cancer have therefore not focused on detailed mechanisms, but have been aimed at mimicking genetic susceptibility to breast cancer observed in humans, and at demonstrating a functional role for molecular lesions observed in end-stage human disease. While Trp53 knockout mice have provided much insight into the role of p53 in tumor suppression, tools that allow specific modulation of the mammary gland have greatly enhanced, and in some cases have been essential to, our understanding of the function of p53 and its interaction with other molecules in protection against breast cancer.

\section{Altering p53 function in the mouse mammary gland}

The function of p53 has been modified genetically in mice in several ways (Table 1). Targeted disruption of the Trp53 gene has been performed by several groups [15-17]. This process removes several exons from the endogenous gene and results in the absence of p53 protein in all tissues of the mouse throughout development and adulthood. Mice homozygous for the Trp53 null allele $\left(\right.$ Trp53 $\left.{ }^{-/}\right)$die at 4-6 months of age, primarily from lymphomas. Only on the BALB/c genetic background have significant numbers of mammary tumors been observed in Trp53+/- mice, mimicking LFS of humans [18].

To study gene function in a particular tissue without the complication of death due to other tumor types (e.g. lymphomas) or embryonic lethality, tissue-specific deletion of genes within the mammary glands has been achieved using conditional knockouts $[19,20]$. In this system, the gene to be deleted is modified by inserting recombination sites (loxP or FRT) both sides of the gene, and it is introduced into the mouse as a targeted insertion. This does not alter gene function until a recombinase is expressed that recombines the chromosome at the two inserted recombination sites, thus deleting the gene segment between them. Tissue-specific expression of the recombinase (Cre for loxP sites, and Flp for FRT sites) achieves the tissue-specific gene deletion. 
Table 1

\begin{tabular}{lcccc}
\multicolumn{1}{l}{ Genetic alterations of the Trp53 gene in mice } & & & \\
\hline Modification & Promoter & Pregnancy required & Effect & No p53 protein \\
\hline $\begin{array}{l}\text { p53 deficient, Trp53- } \\
\text { Mutant p53 transgenes }\end{array}$ & - & No & & References \\
p53-R172H & WAP & Yes & Dominant negative/gain of function & [33,40] \\
$p 53-R 172 L$ & WAP & Yes & Super active p53 & [49,50] \\
\hline
\end{tabular}

WAP, whey acidic protein.

The following promoters are used to target the mammary gland: the whey acidic protein (WAP) promoter, which is turned on exclusively during pregnancy and lactation [19]; the mouse mammary tumor virus (MMTV) promoter, which is expressed constitutively in the mammary gland at low levels but also in a limited number of other tissues, including the salivary gland, and which is responsive to hormones [19]; and the human keratin 14 (K14) gene promoter, which is expressed in the epithelium of numerous tissues including the mammary gland and skin [21].

While K14 is expressed in myoepithelial cells and rarely in luminal epithelial cells of the mammary gland, expression of Cre under the K14 promotor resulted in lacZ reporter gene expression in both luminal and myoepithelial cells, possibly due to $\mathrm{K} 14$ promotor activity in a common progenitor [21]. It must be noted that promotors used to express recombinases may result in permanent genetic changes to cells that only transiently express the recombinase. Promotors must thus be carefully chosen considering their activity throughout development, not just in the adult tissue types.

While a molecular approach is one way to target modifications to the mammary gland, transplantation of mammary epithelium into cleared fat pads is a valuable alternative approach to analyze the effects of gene deletion in the mammary epithelium [22]. With this technique, the mammary ductal rudiments of 3-week-old (prepubescent) mice are surgically removed from the abdominal mammary glands. This leaves the fat pad 'cleared' of mammary epithelium into which donor epithelium can be placed. As the mouse matures, the donor epithelium will grow to fill the mammary gland.

Transplantation of $\operatorname{Trp53^{-/-}}$ epithelium in this manner has demonstrated the role of p53 in protection against mammary tumor formation in the absence of other transgenes [23]. Furthermore, the absence of hormonal requirements to affect gene deletion or to promote transgene expression means that interactions between hormonal factors and the gene deletion can be studied.
Contributions of hormonal simulation to mammary tumorigenesis in the absence of functional p53 have been studied in this manner $[23,24]$.

While tissue-specific gene deletion has not been widely applied to studies of p53 function, overexpression of exogenous genes (i.e. transgenes) under tissue-specific promoters has been used to study $\mathrm{p} 53$ function in the mammary gland. p53 is a tetrameric protein, thus protein from a mutant allele can interact with and disrupt the function of p53 protein from a wild-type allele in a dominantnegative manner. This has been elegantly demonstrated in mice by the breeding of mice transgenic for mutant p53 (Val135) to both wild-type and Trp53/- mice. The mutant transgene was able to accelerate tumor development in wild-type and $\operatorname{Trp} 53^{+/-}$mice but had no effect in Trp53-/mice, indicating its tumor promotion occurred only through disruption of wild-type p53 function [25].

Other mutant Trp53 genes have been overexpressed selectively in the mammary gland under the control of the WAP promoter. These transgenes contain point mutations commonly found in TP53 in human tumors, such as the p53-R172H mutant, which have dominant-negative or gain-of-function properties, and thus in some ways may better represent the human situation than complete absence of gene product [26]. However, the use of the WAP promoter, which is turned on exclusively during pregnancy and lactation, requires that the mice go through at least one and often multiple rounds of pregnancy and lactation to maintain transgene expression. An alternative approach is the use of the MMTV promoter that is expressed constitutively in the mammary gland, but this promoter is also responsive to hormones. Thus, when transgenes are driven by WAP or MMTV promoters, it is not possible to dissect hormonal events that may interact with p53 function in the mammary gland and affect tumorigenesis. To date, the MMTV promoter has not been used to introduce modified p53 genes. However, the MMTV promoter has been used to drive many mammary oncogenes that have been studied in combination with the Trp53- allele, as will be discussed (see Table 3 later). 


\section{Activity of p53 in normal mouse mammary epithelium}

The occurrence of p53 mutations in breast cancer and the high rate of breast cancer in LFS patients pointed to an important role for p53 in the breast. Initial studies of p53-deficient mice (Trp53 ${ }^{+/-}$and $\operatorname{Trp53^{-/-}}$ ) [15-17] did not, however, reveal any essential function for p53 in the mammary gland. The p53-deficient mice did not develop mammary tumors, and both lactation and involution appeared normal. A closer examination at the cellular level of wild-type mice compared with $\mathrm{Trp}_{53^{-/}}$mice, however, revealed a role for p53-dependent apoptosis in the early stages of involution. Removal of pups from the wild-type lactating gland induced p21WAF1 expression, a p53 target gene, within 24-48 hours. This expression was absent in $\operatorname{Trp} 53^{-/-}$mice. Correspondingly, involution in the $\mathrm{Trp}_{53^{-/}}$mice was delayed when examined in the early (days 2-5) weaning period [27]. Other workers have also reported observing fewer apoptotic cells at day 1 of involution in $\mathrm{Trp}_{53^{-/}}$mice compared with control mice [28]. Thus, p53 is important in inducing mammary epithelial apoptosis in response to a physiological stimulus.

The p53 protein is also important in the response of normal mammary epithelium to DNA damaging agents such as $\gamma$-radiation, but responsiveness is greatly affected by the hormonal status of the animal. In normal resting epithelium, whole-body irradiation of mice resulted in minimal increases in p53-dependent transcription of p21WAF1 and apoptosis. Treatment of the mouse with exogenous hormones (pregnant mare serum gonadotrophin and human chorionic gonadotrophin) prior to irradiation, however, produced a strong p53 response [29]. In the physiological setting, this regulation of p53 response by hormones has been demonstrated by the strong induction of $\mathrm{p} 21^{\mathrm{WAF} 1}$ and apoptosis after irradiation during pregnancy and weaning, but by lack of response during lactation and in the virgin state [30]. The absence of p21WAF1 expression and apoptosis in similarly treated Trp53 $3^{-/}$animals demonstrated that these processes are p53 dependent.

This variation in p53 activity in the mammary gland involves many levels of regulation. The p53 mRNA levels are altered across developmental phases, suggesting hormonal regulation of transcription $[27,29]$. However, the virgin gland contains high levels of p53 mRNA and yet does not produce a p53 response to $\gamma$-radiation, indicating that translational and post-translational regulation are also important. Expression of antagonists of p53, such as MDM2, also varies across development stages (Pinkas and Jerry, unpublished data, 2002). However, this does not fully explain the variations in p53 activity. The mechanisms through which hormones modulate $\mathrm{p} 53$ function are yet to be determined.

\section{The role of p53 in mammary tumor development in mouse models} Mammary tumor development in p53-deficient mice While the original $\operatorname{Trp} 53^{-/-}$mice developed normally, they succumbed to a range of tumors, primarily lymphomas, within 6 months. Mammary tumors were notably absent $[15,16]$. To examine the possibility that early death due to lymphoma may be obscuring mammary tumor development in Trp53 ${ }^{-/}$mice, BALB/c-Trp53 ${ }^{-1-}$ mammary epithelium was transplanted into cleared fat pads of wild-type hosts. In this model, spontaneous mammary tumors formed in $60 \%$ of outgrowths with a latency of 50 weeks $[18,23]$, demonstrating that p53 deficiency can promote mammary tumor formation in mice as well as in humans (Table 2). The tumors formed were moderately to poorly differentiated adenocarcinomas with high levels of aneuploidy. The long latency and incomplete penetrance of the phenotype, however, indicated that other genetic events must be required in addition to the loss of p53 for tumors to form.

$\operatorname{Trp53^{+/-}}$ mice survived much longer than $\operatorname{Trp53^{-/-}}$ mice. They also succumbed to lymphomas and sarcomas, however, with mammary tumors accounting for less than $1 \%$ of tumors in $129 / \mathrm{S} v$ and C57BL/ $6 \times 129 / \mathrm{Sv}$ mouse strains [31]. In contrast, when the Trp53- allele was backcrossed onto the BALB/c strain (nine generations), which is known to be more susceptible to mammary tumorigenesis, spontaneous mammary tumors occurred in $55 \%$ of Trp53 ${ }^{+/-}$female mice [18]. Genetic components cooperating with p53 deficiency must thus be present in BALB/c to promote mammary tumor formation, and BALB/cTrp53 $3^{+/-}$mice may serve as a unique model of LFS [18]. Similar to the $\operatorname{Trp53^{-/-}}$ transplant tumors, these tumors were primarily adenocarcinomas, had a long latency of 8-14 months, and the majority were aneuploid. Furthermore, loss of the wild-type allele of Trp53 occurred in all mammary tumors examined, suggesting that this is an important collaborating genetic event in tumor formation [18]. This is similar to observations in LFS, where loss of heterozygosity for TP53 occurred at a high rate in breast cancers [32].

Studies using variations of these two models have explored the interactions between p53 and hormones, the mammary carcinogen 7,12-dimethylbenz[a]anthracene (DMBA), and $\gamma$-radiation in mammary tumorigenesis (Table 2). The Trp53 ${ }^{-1-}$ transplant model has been used to examine the interactions between hormonal stimulation and p53 deficiency in mammary tumorigenesis. Chronic hormonal stimulation in the form of pituitary isografts increased tumor incidence from 60 to $100 \%$, in addition to decreasing the latency (50 to 37 weeks) [23]. This observation indicates that, in the absence of p53, hormonal stimulation is a very potent tumorigenic stimulus. Indeed, further investigation has shown that low doses of 
Table 2

\begin{tabular}{|c|c|c|c|c|c|}
\hline Model & Agent & Incidence (\%) & Latency & Loss of heterozygosity & References \\
\hline $\operatorname{Trp} 53^{-/-}$ & \multicolumn{3}{|c|}{ Death from nonmammary tumors } & & {$[15,16,18]$} \\
\hline \multicolumn{6}{|c|}{ BALB/c mammary epithelium transplants } \\
\hline $\operatorname{Trp53}+/+$ & NT or Pit Stim & 0 & - & & [23] \\
\hline $\operatorname{Trp53^{-/-}}$ & NT & 61 & 50 weeks & & {$[18,23]$} \\
\hline $\operatorname{Trp53^{-/-}}$ & Pit Stim & 100 & 37 weeks & & [23] \\
\hline $\operatorname{Trp} 53^{+/+}$ & DMBA & 4 & 26 weeks & & [23] \\
\hline $\operatorname{Trp5} 53^{-/-}$ & DMBA & 60 & 35 weeks & & [23] \\
\hline $\operatorname{Trp} 53^{+/+}$ & Pit Stim + DMBA & 14 & 27 weeks & & [23] \\
\hline Trp53-1- & Pit Stim + DMBA & 90 & 25 weeks & & [23] \\
\hline \multicolumn{6}{|c|}{ Transgenic FVB WAP-p53-R172H mice } \\
\hline$p 53-R 172 H$ & Pregnancy & $10-15$ & $>1$ year & & [33] \\
\hline Wild type & Pit Stim + DMBA & 85 & 33 weeks & & [33] \\
\hline$p 53-R 172 H$ & Pit Stim + DMBA & 100 & 24 weeks & & [33] \\
\hline \multicolumn{6}{|l|}{$\operatorname{Trp} 53^{+/-}$} \\
\hline B $6 \times 129 \operatorname{Trp} 53^{+/+}$ & Pit Stim + DMBA & 35 & 5.0 months & & [34] \\
\hline B6x129 Trp53+/- & Pit Stim + DMBA & 40 & 4.6 months & No & [34] \\
\hline BALB/c (N9) Trp53+/- & Spontaneous & 55 & 8-14 months & Yes & [18] \\
\hline BALB/c or DBA/2 $\operatorname{Trp} 53^{+/+}$ & $\gamma$-Radiation & 0 & & - & [35] \\
\hline $\mathrm{DBA} / 2(\mathrm{~N} 1-6) \operatorname{Trp5} 3^{+/-}$ & $\gamma$-Radiation & 6 & & Yes & [35] \\
\hline BALB/c (N1-6) Trp53+/- & $\gamma$-Radiation & 41 & & Yes & [35] \\
\hline
\end{tabular}

DMBA, 7,12-dimethylbenz[a]anthracene; NT, no treatment; Pit Stim, hormonal stimulation provided by pituitary isografts; WAP, whey acidic protein.

progesterone, but not estrogen, can promote aneuploidy in morphologically normal Trp53-/- mammary epithelial transplants [24].

Cooperation of the chemical carcinogen DMBA with p53 mutation or p53 deficiency has also been demonstrated in several situations. DMBA treatment alone decreased tumor latency (50 to 35 weeks) in Trp53/- outgrowths [23]. When administered in addition to hormonal stimulation, latency was further reduced (25 weeks). Cooperation was also observed in mice carrying the $p 53-\mathrm{R} 172 \mathrm{H}$ transgene. This transgene, with continuous breeding to promote expression from the WAP promoter, resulted in only $10-15 \%$ spontaneous mammary tumor incidence in mice older than 1 year. However, using pituitary isografts to stimulate maximal transgene expression, the presence of the mutant $p 53-\mathrm{R} 172 \mathrm{H}$ transgene increased the tumor burden and incidence, and decreased the latency of tumors induced by DMBA administration [33]. A trend towards cooperation between $\operatorname{Trp53^{+/}}$ and DMBA treatment with pituitary stimulation has also been reported by Jerry et al. [34], but it was not statistically significant (Table 2).

Similar to spontaneous mammary tumor formation, the ability of $\gamma$-radiation to promote mammary tumorigenesis in Trp53+/- mice is greatly affected by the mouse strain background. With the Trp53- allele backcrossed one to six generations onto either the $\mathrm{DBA} / 2$ or $\mathrm{BALB} / \mathrm{c}$ strain, $\gamma$-radiation significantly increased the incidence of mammary tumors in the BALB/c-Trp53 $3^{+/-}$mice but not in the DBA/2-Trp53 ${ }^{+/-}$mice [35]. This reinforces the importance of modifier genes that can alter phenotypes of tumor susceptibility mutations such as Trp53-.

\section{Loss of p53 function is critical in Brca1-associated and Brca2-associated breast cancer}

In addition to LFS, the identification of the two breast cancer susceptibility genes, BRCA1 and BRCA2, has led to many efforts to mimic in mice the susceptibility to breast cancer in humans incurred by mutations in these genes, and to understand the mechanisms by which they contribute to mammary carcinogenesis. Towards this, five strains of Brca1 knockout mice have been generated (reviewed in [36]), revealing that complete Brca1 deficiency results in embryonic lethality. Brca1 ${ }^{+/-}$mice developed normally but, unlike humans carrying BRCA1 mutations, failed to show increased susceptibility to mammary carcinomas, reminiscent of p53 heterozygous mice and LFS.

Using mice with germline mutations, Cressman et al. demonstrated cooperativity between p53 and Brca1 in mammary tumor formation (Table 3 ), with $10 \%$ of 
Table 3

Cooperation of p53 with other transgenes in mammary tumorigenesis

\begin{tabular}{|c|c|c|c|c|c|c|}
\hline \multirow[b]{2}{*}{ Transgene } & \multirow[b]{2}{*}{ Trp53 genotype } & \multicolumn{2}{|c|}{ Mammary tumor } & \multirow[b]{2}{*}{ Tumor Trp53 status } & \multirow[b]{2}{*}{ Features } & \multirow[b]{2}{*}{ References } \\
\hline & & Occurrence & Latency & & & \\
\hline \multirow[t]{2}{*}{ Brca 1+/- } & $+/+$ & No & & & & [37] \\
\hline & $-/-$ & $10 \%$ & & & & [37] \\
\hline \multirow[t]{2}{*}{ Brca 1Ko/Co } & $+/+$ & Yes & $10-13$ months & Mutations & & [38] \\
\hline & $+/-$ & Accelerated & $6-8$ months & $80 \% \mathrm{LOH}$ & & [38] \\
\hline \multirow[t]{3}{*}{$\mathrm{Brca2}{ }^{\mathrm{Co} / \mathrm{Co}}$} & $+/+$ & No & & & & [21] \\
\hline & $+/-$ & Yes & 360 days & $100 \% \mathrm{LOH}$ & & [21] \\
\hline & $-1-$ & Accelerated & 181 days & & & [21] \\
\hline \multirow[t]{2}{*}{ MMTV-neu } & Wild type & Yes & 234 days & Mutations & Euploid & [40] \\
\hline & $\mathrm{R} 172 \mathrm{H}$ & Accelerated & 154 days & & Aneuploid & [40] \\
\hline \multirow[t]{2}{*}{ WAP-DES } & Wild type & Yes & 21 months & & Euploid & {$[41]$} \\
\hline & $\mathrm{R} 172 \mathrm{H}$ & Accelerated & 14 months & & Aneuploid & {$[41]$} \\
\hline \multirow[t]{4}{*}{ MMTV-Wnt1 } & $+/+$ & Yes & 22.5 weeks & & Euploid & [42] \\
\hline & $+/-$ & Yes (no acceleration) & 23.0 weeks & $50 \% \mathrm{LOH}$ & & [42] \\
\hline & $-1-$ & Accelerated & 11.5 weeks & Ane & loid, $\uparrow$ proliferation & [42] \\
\hline & & & & & s differentiated & [47] \\
\hline \multirow[t]{4}{*}{ MMTV-ras } & $+/+$ & Yes, and salivary tumors & 8.5 months & No mutations & & [43] \\
\hline & $+/-$ & Accelerated & 6.3 months & No LOH, no mutations & & [43] \\
\hline & $-1-$ & Few & & $\uparrow A n$ & loidy, $\uparrow$ proliferation & n [43] \\
\hline & & Salivary tumors dominate & & & & [43] \\
\hline \multirow[t]{3}{*}{ MMTV/c-myc } & $+/+$ & Yes & & & Aneuploid & {$[51]$} \\
\hline & $+/-$ & Few & & $25 \%$ LOH & Aneuploid & [51] \\
\hline & $+/-$ & Lymphomas dominate & & $90 \% \mathrm{LOH}$ & & [51] \\
\hline
\end{tabular}

$\mathrm{LOH}$, loss of heterozygosity; MMTV, mouse mammary tumor virus; WAP, whey acidic protein; WAP-DES = WAP-des(1-3)insulin-like growth factor-I transgene.

Brca 1+/-Trp53/-/- mice developing mammary carcinomas compared with $0 \%$ of Brca1+/-Trp53+/+ mice [37]. With the development of conditional knockouts, $\mathrm{Xu}$ et al. were able to demonstrate more elegantly and sensitively the cooperation between these two genes. In mice with one germline and one conditional mutant allele of Brca1 (Brca1Ko/CoMMTV-Cre), mammary tumors developed after approximately 1 year. The addition of one germline mutation in Trp53 (Brca1Ko/CoMMTV-CreTrp53 ${ }^{+/-}$) accelerated mammary tumor formation to 6-8 months, and most of these tumors showed loss of the wild-type allele of Trp53 [38]. Mutations in Brca1 and Trp53 are thus strongly cooperative in mammary tumorigenesis.

The first attempts to study Brca2 knockout mice similarly found that the mutation was embryonic lethal. The recent generation of conditional Brca2 knockout mice using K14 promoter-driven Cre expression, however, has allowed the study of Brca2 deficiency in the mammary gland [21]. Strikingly, K14cre;Brca2 $\mathrm{Co} / \mathrm{Co}$ females developed no epithelial tumors over 900 days of monitoring, but the absence of p53 (also conditionally knocked out) resulted in all mice developing either skin or mammary carcinomas by 300 days of age. Deficiency of one Trp53 allele was sufficient to promote mammary and skin tumor formation, and all tumors had lost the wild-type allele of Trp53. Disruption of the p53 pathway is thus pivotal in Brca2-associated breast cancer in mice [21]. This is consistent with human breast cancer, where mutations in p53 are seen in a large proportion of BRCA1 and $B R C A 2$ breast cancers $[5,6]$. Interestingly, the majority of the mammary tumors observed in the K14cre;Brca2 ${ }^{\mathrm{Co} / \mathrm{Co}} \operatorname{Trp53}{ }^{\mathrm{Co} / \mathrm{Co}}$ model were carcinomas with basal or myoepithelial cell types, perhaps reflecting the dominant pattern of expression of the K14 promotor in myoepithelial cells [21]. 


\section{p53 cooperates with many pathways involved in mammary tumorigenesis}

In addition to breast cancer susceptibility genes, p53 has been studied for cooperativity with pathways activated in sporadic breast cancer. Transgenic mice overexpressing oncogenes involved in human breast cancer, such as HER-2/Neu, Wnt1 and c-myc, have been generated that develop a high incidence of sporadic mammary carcinomas. By crossing these mice with Trp53 mutant mice or null mice to generate double-transgenic mice, it has been possible to directly demonstrate pathway cooperativity (Table 3). For example, HER-2, a member of the epidermal growth factor receptor family, is overexpressed in approximately $20 \%$ of human breast cancers and is associated with a poor prognosis [39].

Transgenic mice expressing wild-type rat neu under the MMTV promoter (MMTV-neu) develop mammary tumors with an average latency of 234 days that have a high frequency of missense mutations in Trp53 [40]. The cooperativity between the $\mathrm{Neu}$ and p53 pathways was clearly demonstrated by introducing the mutant p53 transgene, p53- $R 172 H$, into these mice, which reduced tumor latency to 154 days [40]. This study in transgenic mice has thus demonstrated strong cooperativity between two genetic lesions common in human breast cancer, and has demonstrated that p53 mutation is an important event in Neu-mediated oncogenesis.

Similar cooperativity was observed between p53 and the insulin-like growth factor pathway. Mice overexpressing an insulin-like growth factor-I analog, the WAPdes(1-3)/GF-I transgene (WAP-DES), demonstrated an $80 \%$ mammary tumor incidence with a latency of 21 months. This is accelerated to only 14 months when combined with the mutant p53 transgene p53- $\mathrm{R} 172 \mathrm{H}$ [41]. Cooperativity between p53 and the Wnt pathway was examined with the Trp53- allele. Female mice transgenic for the Wnt1 mammary oncogene develop mammary tumors with a median latency of 23 weeks. Inheritance of a single defective allele of Trp53 did not confer any increased susceptibility in this model, but the latency was halved to 11.5 weeks with two germline Trp53- alleles [42]. In MMTV-ras mice, which develop both mammary tumors and salivary tumors, being Trp53 ${ }^{+/-}$decreased tumor latency from 8.5 to 6.3 months with little change in the tumor spectrum [43].

In addition to decreasing tumor latency, defects in the p53 pathway in the aforementioned models altered the histological grade of the mammary tumors. While the neu tumors were euploid, neu/p53-R172H bitransgenic tumors were of a higher histological grade and exhibited aneuploidy [40]. WAP-DES/p53- $R 172 H$ bitransgenic tumors showed a higher proportion of tumors with aneuploidy, and in those tumors they showed a higher propor- tion of aneuploid cells than in WAP-DES transgenic tumors [41]. Similar changes were observed in both salivary and mammary tumors of the MMTV-ras with loss of p53 [43]. In the Wnt1 model, mammary tumors lacking p53 showed increased genomic instability with aneuploidy, amplifications, and deletions as shown by karyotype analysis and comparative genomic hybridization [42]. A common feature of mammary tumors lacking functional p53, regardless of the driving oncogenic force, is therefore genomic instability, which is consistent with the profile of p53 as 'guardian of the genome'.

The p53 genotype also affects the tumor growth rate in several of these models. Mammary tumors from Wnt1/Trp53-/- mice show more rapid growth once established compared with Wnt1 tumors with functional p53. This was not due to decreased apoptosis, as there was no effect of p53 genotype on apoptosis levels. However, Trp53 ${ }^{-1-}$ tumors contained more mitotic figures and had more cells in the S phase than did Wnt1 tumors suggesting elevated proliferation rates as an underlying defect [44]. Higher rates of proliferation were also observed in MMTV-ras/Trp53-/- bitransgenic tumors compared to MMTV-ras alone with no alteration in apoptosis levels [43]. This contrasts with animal model studies in other tissues, where accelerated tumor growth due to p53 loss occurred primarily through loss of normal apoptotic function $[45,46]$. The mechanisms by which p53 loss influences tumor progression may thus differ depending on tissue type and/or the oncogenic pathways involved.

The mechanism by which p53 inhibits tumor growth in the Wnt1 model has been investigated. Expression profiling of Wnt1 and Wnt1/Trp53-/- mammary tumors demonstrated that $\operatorname{Trp53}{ }^{-/-}$tumors showed altered expression of several proliferation regulatory genes. Expression of p21WAF1 [47], a p53 target gene, was decreased in tumors from Wnt1/Trp53 ${ }^{-/-}$mice compared to Wnt1 mice. Consistent with this pathway, Wnt1/p21WAF1+/- mammary tumors displayed increased tumor growth rates compared with Wnt1 tumors [48]. The inhibition of tumor growth by p53 may thus be mediated by $\mathrm{p} 21^{\mathrm{WAF} 1}$.

While some effects of p53 on tumor phenotype have been clearly identified, the mechanisms by which p53 protects against cancer in normal mammary glands are more difficult to elucidate. A 'superactive' mutant p53 transgene, $p 53-R 172 L$, expressed under the WAP promoter results in elevated apoptosis rates in normal mammary glands $[49,50]$. Interestingly, this transgene delayed mammary tumor onset induced by DMBA [50] and in transgenic mice expressing transforming growth factor $\alpha$ [26]. In these models, protection against breast cancer by p53 may thus be due to removal of genetically damaged cells by p53-dependent apoptosis. 
In contrast, hyperplasias in Wnt1 mammary glands showed no alteration in apoptosis rates with Trp53 genotype [44], suggesting that p53-mediated apoptosis is not involved in tumor prevention in this model. Furthermore, in this same model, deficiency in p21WAF1 (Wnt1/p21WAF1-Iand Wnt1/p21WAF1+l- mice) was unable to mimic the acceleration due to loss of p53 [48]. In the Wnt1 model, therefore, it appears that protection against tumorigenesis by $\mathrm{p} 53$ occurs through mechanisms other than apoptosis or p21WAF1-mediated cell-cycle arrest, such as maintaining genomic stability.

While p53 cooperates with many models, this is not the case in all models. Female mice carrying the MMTV/c-myc transgene develop mammary carcinomas at 8-10 months of age, with occasional lymphomas developing in males. When only one p53 allele is present, however, mice develop aggressive lymphomas that appear to require loss of the wild-type allele of p53. In contrast, there was no sign of acceleration of mammary tumors, and three-quarters of the mammary tumors that did form had retained the wild-type allele [51], indicating that cooperativity between c-myc and p53 is dependent on tissue type. Regardless of p53 genotype, c-myc tumors showed changes in ploidy and chromosomal aberrations [52]. The lack of tumor acceleration in the presence of c-myc-induced chromosomal instability and the lack of a role for apoptosis and p21WAF1 cell-cycle arrest in the Wnt1 model suggest that maintenance of genomic stability may be a major role for p53 in the prevention of mammary tumors.

\section{SV40 viral oncogene inactivation of p53}

The function of $\mathrm{p} 53$ protein may also be abrogated by expression of the SV40 viral oncogenes. While these viral proteins are not involved in human breast cancer, the viral proteins mimic alterations etiologically linked with human breast cancer. For this reason, several transgenic mice have been generated for studying mammary tumorigenesis [53-57]. However, there are several complications with these models in terms of understanding p53 function in breast cancer.

The first SV40 transgenics contained the SV4O early region, which produces multiple gene products including the large $T$ antigen that functionally inactivates both $\mathrm{pRb}$ and $p 53$, and including the small $t$ antigen that inhibits the serine/threonine phosphatase PP2A. These models therefore do more than just interfere with p53 function, and it is only recently that the contribution of the different components of these gene products has been fully investigated.

A recent study by Goetz et al. [58] generated several WAP-SV40 transgenic lines that produce either large T antigen only (WAP-SVT), small $t$ antigen only (WAP-SVt), or N-terminal truncated large $\mathrm{T}$ antigens (WAP-SVBstBam). All of these lines developed mammary tumors with a lower incidence than the original mice expressing both large $T$ and small $t$ antigens (SVT/t) $(100,64,6-12$ and 0\% for SVT/t, SVT, SVt and SVBst-Bam, respectively) $[57,58]$, indicating many cooperating functions in the SV 40 early genome. Of particular note, however, is the lack of mammary tumors due to the SVBst-Bam transgene that retains the recognized $\mathrm{pRb}$-binding and $\mathrm{p53}$-binding portions of the SV40 genome. In contrast, small $t$ antigen alone was able to result in tumor formation. The p53 and $\mathrm{pRb}$ binding activities of large $\mathrm{T}$ antigen thus require cooperation with small $\mathrm{t}$ antigen and the $\mathrm{N}$-terminal region of large $\mathrm{T}$ antigen to induce mammary tumor formation [58].

\section{p53 and metastases, chemotherapy and gene therapy}

Most mouse models of breast cancer do not display metastatic disease. However, mice expressing the SV40 early genome under the control of the C3(1) component of the rat prostatic steroid binding protein promoter (C3(1)/TAG) [56] develop very aggressive mammary tumors in only 16 weeks, with around $15 \%$ showing lung metastases.

In this model, mice being $\operatorname{Trp} 53^{+/-}$did not significantly alter latency or lead to loss of the remaining allele of Trp53. It did, however, result in more aggressive mammary tumors, as evidenced by increased numbers and sizes of metastases, than did TAG-Trp53/+/ mice [59]. Thus, loss of p53 results in higher grade tumors, more aneuploidy in the primary tumor and promotes metastases. This is consistent with the poorer prognosis of patients with p53negative/mutated tumors versus those without p53 mutations. The protection against metastases by p53 may be mediated by its induction of anti-angiogenesis genes, but these characteristics of p53 have not been fully explored in the transgenic/knockout mouse models to date.

The widely held tenet of chemotherapy is that cells die due to apoptosis, and that the absence of p53 may result in resistance to apoptosis and hence to chemotherapy. However, this has not been demonstrated clearly for nonhematological tumors [60]. Indeed, the p53-mediated apoptotic response to $\gamma$-radiation of mouse tumors was shown to vary among tissues [61]. In DMBA-induced mouse mammary tumors, whole-body irradiation was able to induce nuclear p53 expression and apoptosis. This contrasted other tumor types, such as liver and lung adenomas, where neither p53 expression nor apoptosis was induced by radiation. Thus, while the role of p53 in inducing apoptosis in response to radiation (and probably other chemotherapeutic agents) varies among tissue and tumor types, it would appear that mammary tumors retaining wild-type p53 are one type in which p53 is important [61].

Barrington et al. [62] have made use of transgenic mouse models to examine the role of p53-mediated apoptosis in 
tumor regression in vivo of several chemotherapeutic agents. L-744,832, a potent and selective inhibitor of farnesyltransferase that catalyses an obligatory step in Ras protein activation, leads to the rapid regression of mammary and salivary tumors in MMTV-ras transgenic mice. This occurred by inducing high levels of apoptosis, and tumors arising in ras/Trp53-/- mice regressed at least as efficiently as ras/Trp53 $3^{+/+}$mouse tumors, indicating that the response was largely p53-independent [62]. This contrasts with the effectiveness on ras/Trp53-/- salivary tumors of doxorubicin, which was not able to inhibit tumor growth, and of paclitaxel, which inhibited growth but did not result in regression [63]. Yet both these agents were effective in ras/Trp53 $3^{+/+}$tumors. Interestingly, neither doxorubicin nor paclitaxel efficiently induced apoptosis but, rather, they changed the distribution of cells in the cell cycle. The p53 knockout and transgenic models can thus be used to examine mechanisms and effectiveness of therapeutic agents in the presence and absence of p53. The use of mouse models in this way will probably provide valuable information for the clinic on the tailoring of therapeutic agents that target particular molecular lesions of cancers.

In addition to altering the cell cycle and apoptosis as a means of mediating treatment efficacy, the expression of p53 in mammary tumors can also alter the efficacy of immunomodulatory gene therapy. In mice bearing PyMTinduced tumors, intratumoral injection of adenoviruses carrying either IL-2 or p53 was able to delay tumor growth, but when treated with both viruses together, regression in $65 \%$ of tumors without IL-2 toxicity was obtained [64]. The mechanisms by which p53 enhances this treatment are unclear, but may be due to growth inhibition allowing expansion of the cytotoxic T-lymphocyte response towards the tumors. Only a small percentage of tumor cells in this system are infected by the adenovirus, so while the antitumor growth may be mediated by apoptosis, it is likely to also involve a large bystander effect, and perhaps antiangiogenesis mechanisms [64].

\section{Conclusions}

While initial studies of Trp53 knockout mice did not suggest that p53 was important in the mouse mammary gland, it is now clear that p53 has important roles in normal physiology and tumorigenesis in the mouse. Knockout and transgenic mice with modified p53 functions will thus be useful tools in understanding breast cancer biology and response to therapies. p53 can mediate apoptosis in the mammary gland in response to both physiological and exogenous stresses. Deficiency of p53 alone, in a susceptible genetic setting, is sufficient to allow mammary tumor development in mice, and it has also been demonstrated to be pivotal in breast cancer formation in the context of Brca1 and Brca2 deficiency. We are therefore now able to model in mice three strong breast cancer susceptibility syndromes of humans.
Deficiency of p53 modifies tumor biology, promoting aggressiveness, rapid growth and genetic instability. p53 deficiency in the mouse cooperates with other oncogenic events important to human breast cancer, accelerating mammary tumor formation. Identification of further pathways (and hence modifier genes) with which p53 deficiency cooperates, combined with understanding mechanisms that regulate p53 activity, will greatly enhance our understanding of breast cancer biology and our ability to prevent it. With the complexity of tumor biology and the paracrine activities of p53, such as antiangiogenic activities, the use of p53 transgenic and knockout mice provides important in vivo tools for understanding and developing therapeutic strategies.

\section{Acknowledgements}

Support was provided by Department of Defense Breast Cancer Program award number DAMD17-00-1-0632 (DJJ) and award number DAMD17-01-1-0315 (ACB), administered by US Army Medical Research Acquisition Activity (Fort Detrick, MD, USA) and the National Institutes of Health grant R21CA87531.

\section{References}

1. Coles C, Condie A, Chetty U, Steel C, Evans H, Prosser J: p53 mutations in breast cancer. Cancer Res 1992, 52:5291-5298.

2. Varley JM, McGown G, Thorncroft M, Santibanez-Koref MF, Kelsey AM, Tricker KJ, Evans DG, Birch JM: Germ-line mutations of TP53 in Li-Fraumeni families: an extended study of 39 families. Cancer Res 1997, 57:3245-3252.

3. Akashi M, Koeffler HP: Li-Fraumeni syndrome and the role of the p53 tumor suppressor gene in cancer susceptibility. Clin Obstet Gynecol 1998, 41:172-199.

4. Varley JM, Evans DGR, Birch JM: Li-Fraumeni syndrome - a molecular and clinical review. Br J Cancer 1997, 76:1-14.

5. Crook T, Brooks LA, Crossland S, Osin P, Barker KT, Waller J, Philp E, Smith PD, Yulug I, Peto J, Parker G, Allday MJ, Crompton MR, Gusterson BA: p53 mutation with frequent novel condons but not a mutator phenotype in BRCA1- and BRCA2-associated breast tumours. Oncogene 1998, 17:1681-1689.

6. Greenblatt MS, Chappuis PO, Bond JP, Hamel N, Foulkes WD: TP53 mutations in breast cancer associated with BRCA1 or BRCA2 germ-line mutations: distinctive spectrum and structural distribution. Cancer Res 2001, 61:4092-4097.

7. El-Deiry WS: Regulation of p53 downstream genes. Semin Cancer Biol 1998, 8:345-357.

8. Janus F, Albrechtsen N, Dornreiter I, Wiesmuller L, Grosse F, Deppert $W$ : The dual role model for p53 in maintaining genomic integrity. Cell Mol Life Sci 1999, 55:12-27.

9. Sionov RV, Haupt Y: The cellular response to p53: the decision between life and death. Oncogene 1999, 18:6145-6157.

10. Lakin ND, Jackson SP: Regulation of p53 in response to DNA damage. Oncogene 1999, 18:7644-7655.

11. Venkatachalam S, Shi YP, Jones SN, Vogel H, Bradley A, Pinkel $D$, Donehower LA: Retention of wild-type p53 in tumors from p53 heterozygous mice: reduction of p53 dosage can promote cancer formation. EMBO J 1998, 17:4657-4667.

12. Gottlieb E, Haffner R, King A, Asher G, Gruss P, Lonai P, Oren M: Transgenic mouse model for studying the transcriptional activity of the p53 protein: age- and tissue-dependent changes in radiation-induced activation during embryogenesis. EMBO J 1997, 16:1381-1390.

13. Venkatachalam S, Tyner SD, Pickering CR, Boley S, Recio L, French JE, Donehower LA: Is p53 haploinsufficient for tumor suppression? Implications for the p53+/- mouse model in carcinogenicity testing. Toxicol Pathol 2001, 29(suppl):147154.

14. Colombel M, Radvanyi F, Blanche $M$, Abbou C, Buttyan $R$, Donehower LA, Chopin D, Thiery JP: Androgen suppressed apoptosis is modified in p53 deficient mice. Oncogene 1995, 10:1269-1274. 
15. Donehower LA, Harvey M, Slagle BL, McArthur MJ, Montgomery CA Jr, Butel JS, Bradley A: Mice deficient for p53 are developmentally normal but susceptible to spontaneous tumours. Nature 1992, 356:215-221.

16. Jacks T, Remington L, Williams BO, Schmitt EM, Halachmi S, Bronson RT, Weinberg RA: Tumor spectrum analysis in p53mutant mice. Curr Biol 1994, 4:1-7.

17. Purdie CA, Harrison DJ, Peter A, Dobbie L, White S, Howie SE, Salter DM, Bird CC, Wyllie AH, Hooper ML, Clarke A: Tumour incidence, spectrum and ploidy in mice with a large deletion in the p53 gene. Oncogene 1994, 9:603-609.

18. Kuperwasser C, Hurlbut G, Kittrell F, Medina D, Naber S, Jerry. D: Development of mammary tumors in BALB/c p53 heterozygous mice: A model for Li-Fraumeni Syndrome. Am J Pathol 2000, 157:2151-2159.

19. Wagner KU, Wall RJ, St-Onge L, Gruss P, Wynshaw-Boris A, Garrett L, Li M, Furth PA, Hennighausen L: Cre-mediated gene deletion in the mammary gland. Nucleic Acids Res 1997, 25: 4323-4330

20. Furth PA: Conditional control of gene expression in the mammary gland. J Mammary Gland Biol Neoplasia 1997, 2: 373-383.

21. Jonkers J, Meuwissen $R$, van der Gulden $H$, Peterse $H$, van der Valk $M$, Berns A: Synergistic tumor suppressor activity of BRCA2 and p53 in a conditional mouse model for breast cancer. Nat Genet 2001, 29:418-425.

22. Sekhri KK, Pitelka DR, DeOme KB: Studies of mouse mammary glands. II. Cytomorphology of mammary transplants in inguinal fat pads, nipple-excised host glands, and whole mammarygland transplants. J Natl Cancer Inst 1967, 39:491-527.

23. Jerry $D$, Kittrell $F$, Kuperwasser $C$, Laucirica $R$, Dickinson $E$, Bonilla P, Butel J, Medina D: A mammary-specific model demonstrates the role of the p53 tumor suppressor gene in tumor development. Oncogene 2000, 60:2723-2729.

24. Goepfert TM, McCarthy M, Kittrell FS, Stephens C, Ullrich RL, Brinkley BR, Medina D: Progesterone facilitates chromosome instability (aneuploidy) in p53 null normal mammary epithelial cells. FASEB J 2000, 14:2221-2229.

25. Harvey M, Vogel H, Morris D, Bradley A, Bernstein A, Donehower LA: A mutant p53 transgene accelerates tumour development in heterozygous but not nullizygous p53-deficient mice. Nat Genet 1995, 9:305-311.

26. Murphy KL, Rosen JM: Mutant p53 and genomic instability in a transgenic mouse model of breast cancer. Oncogene 2000, 19:1045-1051.

27. Jerry D, Kuperwasser C, Downing S, Pinkas J, He C, Dickinson E, Marconi S, Naber S: Delayed involution in the mammary epithelium in BALB/c-p53null mice. Oncogene 1998, 17:23052312

28. Li M, Hu J, Heermeier K, Hennighausen L, Furth PA: Apoptosis and remodeling of mammary gland tissue during involution proceeds through p53-independent pathways. Cell Growth Differ 1996, 7:13-20.

29. Kuperwasser C, Pinkas J, Hurlbut G, Naber S, Jerry D: Cytoplasmic sequestration and functional repression of $p 53$ in the mammary epithelium is reversed by hormonal treatment. Cancer Res 2000, 60:2723-2729.

30. Minter LM, Kuperwasser CK, Dickinson ES, Jerry DJ: Cell-cycling status of mammary epithelial cells predicts p53 responsiveness to gamma-radiation. Development 2002 , in press.

31. Donehower LA, Harvey M, Vogel H, McArthur MJ, Montgomery CA Jr, Park SH, Thompson T, Ford RJ, Bradley A: Effects of genetic background on tumorigenesis in p53-deficient mice. Mol Carcinog 1995, 14:16-22.

32. Varley JM, Thorncroft M, McGown G, Appleby J, Kelsey AM, Tricker KJ, Evans DG, Birch JM: A detailed study of loss of heterozygosity on chromosome 17 in tumours from Li-Fraumeni patients carrying a mutation to the TP53 gene. Oncogene 1997, 14:865-871

33. Li B, Murphy KL, Laucirica R, Kittrell F, Medina D, Rosen JM: A transgenic mouse model for mammary carcinogenesis. Oncogene 1998, 16:997-1007.

34. Jerry DJ, Butel JS, Donehower LA, Paulson EJ, Cochran C, Wiseman RW, Medina D: Infrequent p53 mutations in 7,12dimethylbenz[a]anthracene-induced mammary tumors in BALB/c and p53 hemizygous mice. Mol Carcinog 1994, 9:175183.
35. Backlund MG, Trasti SL, Backlund DC, Cressman VL, Godfrey V, Koller $\mathrm{BH}$ : Impact of ionizing radiation and genetic background on mammary tumorigenesis in p53-deficient mice. Cancer Res 2001, 61:6577-6582.

36. Brodie SG, Deng C: BRCA1-associated tumorigenesis: what have we learned from knockout mice? Trends Genet 2001, 17: S18-S22.

37. Cressman VL, Backlund DC, Hicks EM, Gowen LC, Godfrey V, Koller BH: Mammary tumor formation in p53- and BRCA1-deficient mice. Cell Growth Differ 1999, 10:1-10

38. Xu X, Wagner KU, Larson D, Weaver Z, Li C, Ried T, Hennighausen L, Wynshaw-Boris A, Deng CX: Conditional mutation of Brca1 in mammary epithelial cells results in blunted ductal morphogenesis and tumour formation. Nat Genet 1999, 22:37-43.

39. Barnes DM, Camplejohn RS: P53, apoptosis, and breast cancer. J Mammary Gland Biol Neoplasia 1996, 1:163-175.

40. Li B, Rosen JM, McMenamin-Balano J, Muller WJ, Perkins AS: neu/ERBB2 cooperates with p53-172H during mammary tumorigenesis in transgenic mice. Mol Cell Biol 1997, 17: 3155-3163.

41. Hadsell DL, Murphy KL, Bonnette SG, Reece N, Laucirica R Rosen JM: Cooperative interaction between mutant p53 and des(1-3)IGF-I accelerates mammary tumorigenesis. Oncogene 2000, 19:889-898.

42. Donehower LA, Godley LA, Aldaz CM, Pyle R, Shi YP, Pinkel D, Gray J, Bradley A, Medina D, Varmus HE: Deficiency of p53 accelerates mammary tumorigenesis in Wnt-1 transgenic mice and promotes chromosomal instability. Genes Dev 1995, 9:882-895

43. Hundley JE, Koester SK, Troyer DA, Hilsenbeck SG, Subler MA Windle JJ: Increased tumor proliferation and genomic instability without decreased apoptosis in MMTV-ras mice deficient in p53. Mol Cell Biol 1997, 17:723-731.

44. Jones JM, Attardi L, Godley LA, Laucirica R, Medina D, Jacks T, Varmus HE, Donehower LA: Absence of p53 in a mouse mammary tumor model promotes tumor cell proliferation without affecting apoptosis. Cell Growth Differ 1997, 8:829-838.

45. Symonds H, Krall L, Remington L, Saenz-Robles M, Lowe S, Jacks $\mathrm{T}$, van Dyke $\mathrm{T}$ : p53-dependent apoptosis suppresses tumor growth and progression in vivo. Cell 1994, 78:703-711.

46. Howes KA, Ransom N, Papermaster DS, Lasudry JG, Albert DM, Windle JJ: Apoptosis or retinoblastoma: alternative fates of photoreceptors expressing the HPV-16 E7 gene in the presence or absence of p53. Genes Dev 1994, 8:1300-1310.

47. Cui XS, Donehower LA: Differential gene expression in mouse mammary adenocarcinomas in the presence and absence of wild type p53. Oncogene 2000, 19:5988-5996.

48. Jones JM, Cui XS, Medina D, Donehower LA: Heterozygosity of p21 WAF1/CIP1 enhances tumor cell proliferation and cyclin D1associated kinase activity in a murine mammary cancer model. Cell Growth Differ 1999, 10:213-222.

49. Li B, Greenberg N, Stephens LC, Meyn R, Medina D, Rosen JM: Preferential overexpression of a $172 \mathrm{Arg} \rightarrow$ Leu mutant p53 in the mammary gland of transgenic mice results in altered lobuloalveolar development. Cell Growth Differ 1994, 5:711-721.

50. Li B, Kittrell FS, Medina D, Rosen JM: Delay of dimethylbenz[a]anthracene-induced mammary tumorigenesis in transgenic mice by apoptosis induced by an unusual mutant p53 protein. Mol Carcinog 1995, 14:75-83.

51. Elson A, Deng C, Campos-Torres J, Donehower LA, Leder P: The MMTV/c-myc transgene and p53 null alleles collaborate to induce T-cell lymphomas, but not mammary carcinomas in transgenic mice. Oncogene 1995, 11:181-190.

52. McCormack SJ, Weaver Z, Deming S, Natarajan G, Torri J, Johnson MD, Liyanage M, Ried T, Dickson RB: Myc/p53 interactions in transgenic mouse mammary development, tumorigenesis and chromosomal instability. Oncogene 1998, 16: 2755-2766.

53. Tzeng YJ, Guhl E, Graessmann M, Graessmann A: Breast cancer formation in transgenic animals induced by the whey acidic protein SV40 T antigen (WAP-SV-T) hybrid gene. Oncogene 1993, 8:1965-1971.

54. Li M, Lewis B, Capuco AV, Laucirica R, Furth PA: WAP-TAg transgenic mice and the study of dysregulated cell survival, proliferation, and mutation during breast carcinogenesis. Oncogene 2000, 19:1010-1019. 
55. Schulze-Garg C, Lohler J, Gocht A, Deppert W: A transgenic mouse model for the ductal carcinoma in situ (DCIS) of the mammary gland. Oncogene 2000, 19:1028-1037.

56. Green JE, Shibata MA, Yoshidome K, Liu ML, Jorcyk C, Anver MR, Wigginton J, Wiltrout R, Shibata E, Kaczmarczyk S, Wang W, Liu ZY, Calvo A, Couldrey C: The C3(1)/SV40 T-antigen transgenic mouse model of mammary cancer: ductal epithelial cell targeting with multistage progression to carcinoma. Oncogene 2000, 19:1020-1027.

57. Santarelli R, Tzeng YJ, Zimmermann C, Guhl E, Graessmann A: SV40 $\mathrm{T}$-antigen induces breast cancer formation with a high efficiency in lactating and virgin WAP-SV-T transgenic animals but with a low efficiency in ovariectomized animals. Oncogene 1996, 12:495-505.

58. Goetz F, Tzeng YJ, Guhl E, Merker J, Graessmann M, Graessmann A: The SV40 small $t$-antigen prevents mammary gland differentiation and induces breast cancer formation in transgenic mice; truncated large T-antigen molecules harboring the intact $\mathrm{p53}$ and $\mathrm{pRb}$ binding region do not have this effect. Oncogene 2001, 20:2325-2332.

59. Maroulakou IG, Shibata MA, Jorcyk CL, Chen XX, Green JE: Reduced p53 dosage associated with mammary tumor metastases in C3(1)/TAG transgenic mice. Mol Carcinog 1997, 20:168-174.

60. Brown JM, Wouters BG: Apoptosis, p53, and tumor cell sensitivity to anticancer agents. Cancer Res 1999, 59:1391-1399.

61. Kemp CJ, Sun S, Gurley KE: p53 induction and apoptosis in response to radio- and chemotherapy in vivo is tumor-typedependent. Cancer Res 2001, 61:327-332.

62. Barrington RE, Subler MA, Rands E, Omer CA, Miller PJ, Hundley JE, Koester SK, Troyer DA, Bearss DJ, Conner MW, Gibbs JB, Hamilton K, Koblan KS, Mosser SD, O'Neill TJ, Schaber MD, Senderak ET, Windle JJ, Oliff A, Kohl NE: A farnesyltransferase inhibitor induces tumor regression in transgenic mice harboring multiple oncogenic mutations by mediating alterations in both cell cycle control and apoptosis. Mol Cell Biol 1998, 18: 85-92.

63. Bearss DJ, Subler MA, Hundley JE, Troyer DA, Salinas RA, Windle $\mathrm{JJ}$ : Genetic determinants of response to chemotherapy in transgenic mouse mammary and salivary tumors. Oncogene 2000, 19:1114-1122.

64. Putzer BM, Bramson JL, Addison CL, Hitt M, Siegel PM, Muller WJ, Graham FL: Combination therapy with interleukin-2 and wild-type p53 expressed by adenoviral vectors potentiates tumor regression in a murine model of breast cancer. Hum Gene Ther 1998, 9:707-718. 